\title{
Building capacity to utilize operations research: Strategies and lessons learned
}

James R. Foreit

Population Council

Follow this and additional works at: https://knowledgecommons.popcouncil.org/departments_sbsr-rh

Part of the Demography, Population, and Ecology Commons, Family, Life Course, and Society

Commons, International Public Health Commons, Medicine and Health Commons, and the Quantitative, Qualitative, Comparative, and Historical Methodologies Commons How does access to this work benefit you? Let us know!

\section{Recommended Citation}

Foreit, James R. 2006. "Building capacity to utilize operations research: Strategies and lessons learned," FRONTIERS Program Brief. Washington, DC: Population Council. 


\section{Building Capacity to Utilize Operations Research: Strategies and Lessons Learned}

$\mathrm{T}$ he effectiveness of development assistance depends on good decisionmaking. Many donors and international health agencies such as the United States Agency for International Development (USAID), the United Kingdom's Department for International Development (DFID), and the World Health Organization (WHO) are placing more emphasis on the utilization of research results for policy and program development. Yet, while there is a long tradition of training researchers to produce research, there are few lessons on how to teach managers to request and use research results for making program decisions.

Addressing this gap has been a major strategy of the Population Council's Frontiers in Reproductive Health Program (FRONTIERS). Since its inception in 1998, FRONTIERS has complemented its support for operations research (OR) with an evolving range of capacity building activities. The purpose of this capacity building is to increase the number of program managers and researchers who can understand and conduct $\mathrm{OR}$ and utilize the resulting findings. As of 2005, over 700 program managers and researchers from 54 countries had participated in FRONTIERS capacity building activities, including courses, training of trainers, infrastructure development efforts, and costing studies.

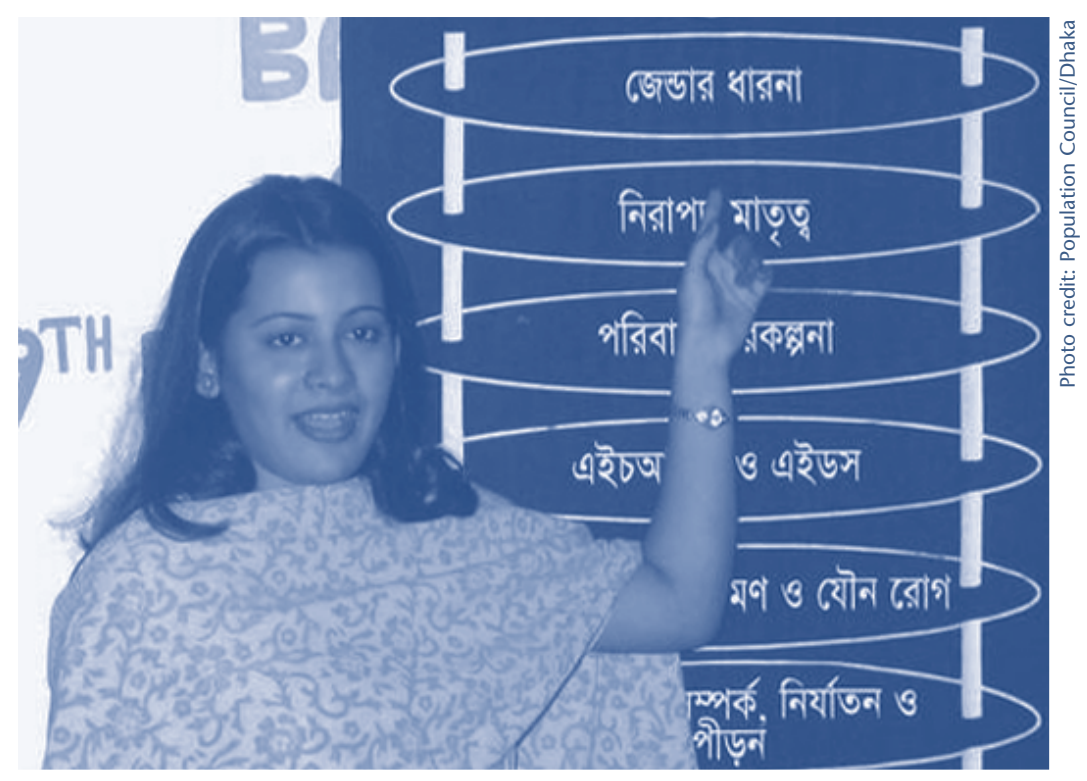

Training session in Bangladesh

This Program Brief presents lessons learned through FRONTIERS capacity building work in fostering the increased use of operations research by family planning and reproductive health programs.

\section{The problem: Supporting evidence- based program decisionmaking}

Operations research is the study of factors under the control of program managers for the purpose of improving program access, quality, impact, and sustainability (Foreit and Frejka 1998). Usually the research takes the form of intervention research, which tests one or more approaches to a given problem. Successful OR requires a close collaboration between the program manager and the research team during the design, implementation, monitoring, analysis, and dissemination phases of the research project.

In theory, OR is commissioned research involving a consumer and a producer. The program manager-the consumer of research findings-identifies an important service delivery problem and recruits a researcher-the producer of the research-to test alternative solutions to the problem. The manager then decides between alternatives using the information generated by the research. Unfortunately, program managers (research consumers) often do not see how research and evidence contribute to better decisionmaking. They often rely on expert opinion, experience, or trial and error, the quality 
of which is not always reliable. Even if program managers do request operations research, there is a limited pool of researchers (research producers) who have enough knowledge of family planning and reproductive health program operations to design relevant studies.

\section{Selecting partners for capacity building}

Because of the dual nature of the utilization problem-few managers who demand OR and few researchers with sufficient understanding of programs to produce relevant OR-the solution must go beyond offering traditional courses in research design and methodology to researchers alone. The FRONTIERS strategy involves developing courses to bring together researchers and managers to design OR studies relevant to their work. These studies can be on testing new service delivery models or products, research on scale-up and replication, behavioral research on clients and providers, or eco-

\section{Box 1.}

\section{FRONTIERS capacity building courses}

FRONTIERS capacity building courses were developed to prepare both researchers and program managers to conduct operations research and to value and use the research findings. The Program developed a series of two- to four-week courses for use by research, training, and service delivery organizations. The courses include modules on identifying program problems, testing solutions, designing intervention studies, and utilization and dissemination. During the full OR in Reproductive Health course, researchers and managers work together and develop a proposal for a brief, low-cost OR study that is submitted for donor funding. Proposals have been funded by a variety of donors: USAID Missions, USAID collaborating agencies, local research and service organizations, and international organizations including the World Health Organization, the International Council on Management of Population Programs, and the International Planned Parenthood Federation.

Other courses address the need for shorter training sessions, training for specific groups such as managers, or instruction on specific skills. A sample of the courses includes the following:

- OR in Reproductive Health (10 days)

- OR Short Course for Managers (5 days)

- OR Short Course for U.S. Public Health Students (5 days)

- Scientific Writing for Reproductive Health Programs (3 days)

- Assessing Clients' Willingness to Pay for Services (1 day)

- Experimental Design (1 semester - 16 weeks)

- Financial Sustainability (5 days)

nomic analysis. The Program has developed 10 courses based on the needs of local training organizations (see Box 1).

Capacity building is a long-term effort requiring close collaboration with local partners. To maximize the likelihood that capacity building activities will be sustainable, FRONTIERS selects organizations that are relatively large within the local environment, or that provide key reproductive health services and/or products. The Program tries to work with service organizations or training and research institutions that will eventually be able to conduct and utilize OR without FRONTIERS assistance. To be selected, organizations should already have some evaluation capacity and be willing to utilize operations research results in program decisionmaking.

The following lessons have emerged from FRONTIERS experience in capacity building:

\section{Building capacity for OR} requires training research consumers (program managers) as well as research producers (researchers).

2. Capacity building for OR entails a long-term strategy including collaborative institutional relationships, sustained technical assistance, and multiple opportunities for actual research.

3. Capacity building requires resource leveraging and cost sharing. 


\section{Training research consumers and research producers}

The FRONTIERS training strategy emphasizes the practical benefits of OR within organizations. Guiding principles include the following:

\section{Train managers and researchers from the same organization together}

Because OR requires collaboration between managers and researchers, FRONTIERS trains managers and researchers from the same institution together in its two-week OR in Reproductive Health workshop. Training more than one person from the same organization also helps create the critical mass of OR producers and consumers that an organization needs to sustain and utilize operations research effectively. The FRONTIERS Program has trained a wide variety of health professionals including policymakers, program managers, service providers, and researchers from nongovernmental institutions, government health programs, research institutions, donors, and universities.

\section{Emphasize intervention research}

Intervention research, which tests the effect of one or more approaches to a program problem, is often a new area for both researchers and managers. Because OR is designed to improve processes that are under the control of program managers, the technical content of the workshop introduces participants to the concepts of experimental design and techniques for studying the effect of interventions. Courses for researchers familiarize participants with intervention study techniques and with reproductive health program processes, costs, and outcomes. Courses for managers describe the research process from problem identification through research design, monitoring, and analysis.

\section{Focus on high-interest topics} Motivation to use OR increases when the research is directly relevant to high-priority program problems. During the workshop, managers and researchers identify an operational problem in their own organization, and then work together to produce a draft of an operations research proposal. Recently, FRONTIERS began organizing proposal development workshops around a common high-priority program problem, i.e., financial sustainability of services and programs.

\section{Combine training with sub- sequent research experience} Conducting a successful operations research project is one of the most effective techniques for motivating managers to institutionalize the use of OR in their organization. Providing opportunities for hands-on experience in conducting and using research is key. Thus, FRONTIERS encourages workshop participants to develop proposals for OR studies relevant to their work-to test new service delivery models or products, behavioral research, or economic analysis. Proposals developed at workshops are submitted for funding to organizations that support research. As of 2005, 30 proposals had been accepted for funding by organizations including WHO, USAID missions and cooperating agencies, and local agencies such as the All India Institute of Medicine and the Ministry of Health in Bolivia. Examples include a project on introducing the partograph (a monitoring tool developed by WHO to document the progress of labor and conditions of mother and fetus) as an obstetric best practice in Ukraine, and a study on integrating postabortion care with other reproductive health services in Bolivia. FRONTIERS itself has funded an additional 11 lowcost (approximately $\$ 15,000$ each), short-duration (less than one year) financial sustainability research proposals on topics such as cost recovery, cost control, and income generation.

\section{Long-term strategies for sustained capacity}

The FRONTIERS capacity building strategy assumes that longterm involvement is necessary to develop OR skills and provide substantial OR experience, both of which are necessary for institutionalization of OR.

\section{Ongoing collaboration with training and research institutions}

FRONTIERS helps a small number of international teaching and research centers to create the 


\section{Box 2. \\ Institutionalizing OR in local organizations}

FRONTIERS has established long-term relationships with the Cairo Demographic Center (CDC) in Egypt, and the International Institute of Population Studies (IIPS) in Mumbai, India to build their capacity to teach and conduct OR-eventually without outside assistance. Both centers were founded as demographic research organizations but have broadened their focus to include topics such as reproductive health; also they have government support and are stakeholders in the policy process. Both CDC and IIPS offer graduate degree programs and shortterm training, and attract students internationally.

capacity to conduct OR training and technical assistance with minimal outside assistance (see Box 2). Institutional strengthening of OR producer organizations is an incremental process that begins with an agreement specifying the expectations and activities of both parties and providing for funds and technical assistance. The first activity is an OR orientation course for the organization's staff, followed by one or two jointly conducted short courses and proposal development workshops. The first courses entail considerable FRONTIERS staff participation that diminishes over time until the organization's staff is able to teach the courses unaided. After about a year, the organization may add an OR course to its degree or certificate curriculum, taught completely by its own staff. Over time, FRONTIERS maintains its involvement by pre-testing new courses and training materials at the organization and collaborating on operations research projects.

The staff members of these organizations are skilled researchers and teachers, but they usually have little experience with OR. For this reason, a key element in the training of OR trainers is providing them with hands-on experience working with service delivery programs. As a result of FRONTIERS training, CDC and IIPS have added operations research to their degree programs, and have developed short courses for experienced researchers and managers. Collaborating staff members participate in FRONTIERS operations research projects to increase their firsthand experience with OR.

Both organizations have continued to conduct OR. IIPS has collaborated with Indian health authorities on OR studies on a number of reproductive health themes. CDC has worked on several operations research projects in Egypt on quality of care and economic evaluation.

\section{Ongoing collaboration with service delivery programs}

OR capacity building in a service delivery organization always includes operations research studies, and agency staff participates in these studies at all levels ranging from data collection such as interviewing clients to setting the parameters for the research design. The operations research studies are designed to be brief and low-cost because, once FRONTIERS involvement ends, most service delivery organizations are unlikely to conduct globally relevant research studies, which are often lengthy and more costly.

\section{Support during the learning process}

The ability to use operations research, like the ability to produce OR, develops incrementally over time. When FRONTIERS funds a proposal from one of the financial sustainability workshops, it also provides the organization with mentoring so that the staff acquires the skills (such as per-unit costing and break-even analysis) to conduct similar activities without outside assistance. If the results of the initial research project are used by the organization, and if their staff masters the research skills transferred during the study, FRONTIERS will fund subsequent activities with that organization to work on new problems and build new skills.

Institutional strengthening in a service delivery organization can go beyond providing resources and technical assistance for training and research. In Bolivia, for example, FRONTIERS is helping the Ministry of Health (MOH) to develop its own policies for conducting research. FRONTIERS activities are being designed to assist the $\mathrm{MOH}$ in drafting the policy that will establish a 
"Health Research Roundtable" within the ministry with the mandate to set $\mathrm{MOH}$ research priorities, establish and monitor research quality, ensure compliance with ethical guidelines, and distribute funds for commissioned research with the ministry.

\section{Long-term technical assistance}

Given the number and variety of activities that must occur to build the capacity of either research or service delivery organizations to produce and use OR without major outside assistance, collaborations must be relatively long-term. For example, FRONTIERS has been working with CDC in Egypt since 1998. Not all FRONTIERS attempts at long-term relationships have been successful, however (see Box 3).

\section{- South-to-South training}

When possible, FRONTIERS uses staff from developing country organizations to facilitate OR training. FRONTIERS also encourages course participants to become instructors themselves. Two of the most successful Russian-speaking participants at the first Eastern European OR course, held in Romania, were given additional training to act as trainers at a subsequent course, held in Kazakhstan, for Russian-speaking participants from Central Asia.

\section{On-the-job training}

Although FRONTIERS focuses on building organizational capacity, the Program also provides onthe-job training for fellows and interns.

\section{Box 3.}

\section{Not all capacity building efforts are successful}

A variety of factors can inhibit the success of OR capacity building. In El Salvador, at the request of the Ministry of Health $(\mathrm{MOH})$, FRONTIERS began capacity building for the $\mathrm{MOH}$ to conduct operations research. Activities, which included forming an operations research committee inside the $\mathrm{MOH}$ and seminars for $\mathrm{MOH}$ staff from 18 of the country's departments, resulted in 18 separate proposals. To reduce the number, a five-day meeting was held where participants collaborated to produce just five proposals.

The proposals were approved, but before the studies could be launched, a dengue epidemic broke out. The ministry subsequently decided to limit implementation of the proposals to one department. However, this necessitated a second round of OR training. Soon after retraining was completed, an earthquake struck El Salvador. Among the worst hit areas in the country was the department selected as the OR project site. As the country began to recover from the earthquake, FRONTIERS again opened discussions with local stakeholders. FRONTIERS was asked to conduct three more research methodology workshops. Three years had elapsed, and many individuals were trained, but there was no output in terms of research conducted (Vernon and Brambila 2002).
The objective of the fellowship program is to increase highlevel OR manpower resources in developing countries. Usually, FRONTIERS supports three fellows at any one time. Fellows, who work in FRONTIERS country offices, begin by working with a senior researcher on ongoing OR projects. They take on increasing responsibility until they are capable of designing, monitoring, and analyzing their own studies and, when possible, presenting and publishing the findings.

The objective of the intern program is to expose future managers and researchers to actual operations research activities. Interns work for varying lengths of time in the FRONTIERS
Washington, DC office, and are guided by an experienced staff member in areas such as policy development, data analysis, or synthesis and dissemination.

In Bangladesh, FRONTIERS has provided substantial technical assistance to the Directorate General of Family Planning (DGFP) and nongovernmental family planning service delivery organizations to introduce emergency contraception in the national program. Over the past six years, this assistance has built the capacity of public sector service providers and program managers in monitoring and evaluating the program impact. From the very beginning, DGFP staff was involved in the operations research, and government institutions were involved in the 
training exercises. This involvement enabled DGFP staff to become completely competent in the utilization of the research findings.

\section{Other forms of capacity building}

Building capacity is a multi-faceted activity. FRONTIERS capacity building also includes the provision of technical assistance to national counterpart organizations during the process of research design and implementation in its OR projects. In these projects, FRONTIERS partners with over 140 local institutions in 37 countries. Through these partnerships in OR projects, partner institutions in developing countries have increased their ability to define their needs for evidence, and enhanced their capacity to both produce and use evidence for critical decisionmaking (see Box 4).

\section{Leveraging resources to increase support for operations research}

Building capacity for reproductive health OR in developing countries requires a substantial commitment. FRONTIERS can provide only a small part of the needed financial and technical assistance. Therefore, the Program has adopted a strategy of resource leveraging to increase the number and type of capacity building activities.

\section{Cost sharing}

Typically, FRONTIERS seeks financial collaboration in conducting OR courses and in funding research proposals developed at the courses. The World Health Organization (WHO) is FRONTIERS major collaborator in capacity building. In the FRONTIERS/WHO collaboration, for example, FRONTIERS organized OR courses at WHO collaborating centers in Kazakhstan, Mali, Romania, and Thailand. WHO funded all participant and venue costs while FRONTIERS provided instructors and materials. In Asia, collaborators such as CARE, the United Nations Population Fund (UNFPA), Partners in Population and Development, the International Council on Management of Population Programs (ICOMPP), the International Planned Parenthood Federation (IPPF), and the All India Institute of Medicine have covered more than half of the local direct costs of participants at nine FRONTIERS workshops (Khan et al. 2006) (see Figure 1).

Figure 1.

\section{Leveraging financial resources in Asian workshops: Coverage of local costs}

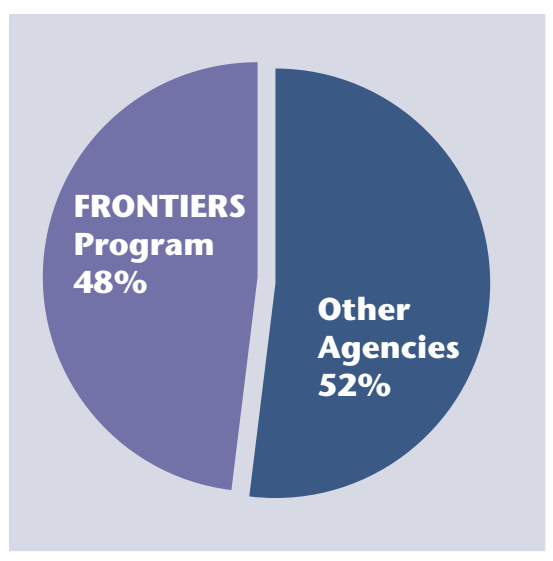

\section{Human resources}

Reproductive health is a broad topic. Depending on the setting, it includes everything from HIV/AIDS prevention and treatment to ante- and postnatal care and well-child services. No single group can provide the staff expertise necessary to build operations research capacity in all topics (Population Council and World Health Organization 2003). WHO has financed, organized, and provided curriculum development and instructors for courses at WHO collaborating centers in Africa, Asia, and Eastern Europe. Collaboration has made it possible to offer a greater number and type of courses, and helped finance the introduction of OR in new geographic areas, the training of trainers, and funding of OR studies. In addition to UNPFA, Partners in Population and Development, and ICOMP, the Reproductive Health Alliance Europe is another organization that has provided OR capacity building resources. Additionally, Egyptian, Ecuadorian, Romanian, and Ugandan service delivery organizations have provided trainers, as have research groups such as the Center for Studies and Research on Population for Development (CEFOREP) in Mali, Makerere University in Uganda, India's Center for Operations Research and Training (CORT), and the Russian Academy of Medical Science. 
Box 4.

\section{Other forms of capacity building}

Over 170 operations research projects supported by FRONTIERS in 37 countries around the globe also contribute to capacity building. A few examples are below:

The Christian Health Association of Ghana (CHAG) is working with FRONTIERS to determine the full economic costs of selected reproductive health services offered at four faith-based organizations. FRONTIERS staff held a workshop for CHAG staff to prepare them to collect data. The one-week workshop introduced participants to costing and provided practical guidance on how to collect all of the cost elements.

In Egypt, FRONTIERS is working closely with the Ministry of Health and Population on implementing an intervention to promote optimal birth spacing. The trainers were recruited from central ministry and governorate offices. FRONTIERS staff provided coaching to those trainers on developing their presentations and conducting the sessions. The involvement of ministry staff in the study design, selection of clinics, and review of data collection instruments has resulted in their appreciation of the role of $\mathrm{OR}$ and understanding of concepts such as threats to validity and sustainability.

\section{Conclusion}

Operations research is an important tool for identifying approaches to improve programs and increase the quality and sustainability of reproductive health care services. Hence it is vital not only to increase the pool of qualified producers of research in developing countries, but also to enhance the skills of consumers-program managers who will request studies and use the information they generate. FRONTIERS experience has shown that it is necessary to:

(1) train researchers, managers, service providers, and other potential users in research methods and utilization of findings, and provide opportunities for hands-on experience in conducting and using research; (2) develop long-term relationships; and (3) leverage support from a wide variety of partners. OR capacity building is essential to the identification of effective reproductive health care strategies and programs, and should be considered a best practice.

\section{References}

Foreit, James R. and Tomas Frejka (eds.). 1998. Family Planning Operations Research: A Book of Readings. New York: Population Council.

Khan, M.E. et al. 2006. "Developing regional capacity in operations research and economic evaluation in South Asia," FRONTIERS Final Report. Washington, DC: Population Council.

Population Council, Frontiers in Reproductive Health Program and World Health Organization, Department of Reproductive Health and Research. 2003. "Expanding Capacity for Operations Research in Reproductive Health: Summary Report of a Consultative Meeting." Geneva: World Health Organization.

Vernon, Ricardo and Carlos Brambila. 2002. "Operations research training and technical assistance in El Salvador," FRONTIERS Final Report. Washington, DC: Population Council.

\section{Operations research training resources available from FRONTIERS}

Fisher, Andrew A. and James

R. Foreit. Designing HIV/ AIDS Intervention Studies: An Operations Research Handbook. New York: Population Council. (English)

Foreit, James R. and Tomas Frejka (eds.). 1998. Family Planning Operations Research: A Book of Readings. New York: Population Council. (English, French, and Spanish)
Foreit, Karen G. Fleischman and James R. Foreit. 2004. "Willingness to pay surveys for setting prices for reproductive health products and services: A user's manual," FRONTIERS Report. Washington, DC: Population Council. (English, French, and Spanish)

Available by request from frontiers@pcdc.org or on the FRONTIERS website at www.popcouncil.org/frontiers. 
Frontiers in Reproductive Health Program (FRONTIERS) Population Council

4301 Connecticut Avenue, NW, Suite 280

Washington, DC 20008

Telephone: (202) 237-9410

Facsimile: (202) 237-8410

E-mail: frontiers@pcdc.org

www.popcouncil.org/frontiers

The Population Council is an international, nonprofit, nongovernmental institution that seeks to improve the wellbeing and reproductive health of current and future generations around the world and to help achieve a humane, equitable, and sustainable balance between people and resources. The Council conducts biomedical, social science, and public health research and helps build research capacities in developing countries. Established in 1952, the Council is governed by an international board of trustees. Its New York headquarters supports a global network of regional and country offices.

\section{Frontiers in Reproductive Health Program Brief No. 5}

Author: James R. Foreit

Editors: Stephanie Joyce, Laura Raney

Design: Vincent Hughes Visualization

The assistance of the following reviewers is appreciated: Sarah Harbison, Patricia Stephenson, and John Townsend.

Suggested citation: Foreit, James R. 2006. "Building capacity to utilize operations research: Strategies and lessons learned," FRONTIERS Program Brief No. 5. Washington, DC: Population Council.

The Frontiers in Reproductive Health Program (FRONTIERS) applies systematic research techniques to improve delivery of family planning and reproductive health services and influence related policies. FRONTIERS is funded by the U.S. Agency for International Development (USAID) and led by the Population Council in collaboration with Family Health International.

This publication was made possible through support provided by USAID under the terms of Cooperative Agreement No. HRN-A-00-98-00012. The opinions expressed herein do not necessarily reflect the views of USAID.

\section{(c) 2006 the Population Council, Inc.}

This publication may be reproduced in whole or in part without permission of Population Council provided full source citation is given and the reproduction is not for commercial purposes.

ISSN 1546-6612 